\title{
Performance Analysis of An Arduino Based Calibration and Temperature Control System for A Refractance Window Dryer
}

\section{Raymonds Mutumba ${ }^{1}$, Julia Kigozi ${ }^{1}$, Peter Tumutegyereize ${ }^{1}$, Shaffic Ssenyimba ${ }^{1}$ and John Muyonga ${ }^{2}$}

\author{
${ }^{1}$ Department of Agricultural and Biosystems Engineering, \\ Makerere University, Kampala, Uganda \\ 2Department of Food Technology and Nutrition, \\ Makerere University, Kampala, Uganda
}

\author{
*Corresponding author details: Julia Kigozi; jbulyakigozi@yahoo.com
}

\begin{abstract}
Automated control of temperature in fruit dryers is important for product quality and retention of nutrient content. In this study, the continuous refractance window dryer (RWD) was calibrated for drying temperature to enable the dryer to be set to dry a wide range of products. The drying operation in a RWD is carried out over a bed of hot water. The calibration system comprised of a computer program, calibrated knob, arrangement of sensors and output components. A computer program was successfully written in Arduino environment and a circuit board connected. A DS18B20 sensor was used to read the hot water temperature and a 5V potentiometer employed to vary the voltage as it corresponds to the desired water temperature. The system calibration focused on drying temperatures for mango, tomato and pineapple, but it can be applied to any other food products since the optimum drying temperature for most food products falls within the considered range. A calibration equation relating potentiometer voltage and temperature was formulated with the potentiometer maximum angular sweep found to be $295^{\circ}$. This angular sweep corresponded with $94.9996^{\circ} \mathrm{C}$ as the maximum calibration temperature. The system was found to be $97.6 \%$ accurate at attaining the desired temperature. A calibrated label was developed and marked accordingly. The developed system was simple to operate and robust throughout the testing hence it can be recommended for similar machines.
\end{abstract}

Keywords: automation; calibration; temperature; refractance window dryer

\section{INTRODUCTION}

According to Carmignato (2019), calibration is the operation that establishes a relationship between the quantity values provided by measurement standards with the corresponding indication provided by a measuring instrument or system. The operation further uses this information to establish a relation for obtaining a measurement result from an unknown value. A calibration may be expressed by a statement, calibration function, calibration diagram, calibration curve, or calibration table (JCGM, 2008). In some cases, calibration may consist of an additive or multiplicative correction of the indication with associated measurement of the uncertainty. According to Michell Instruments (2015), the process of deciding which calibration system is best suited to a manufacturer's needs is dependent on the devices to be calibrated and the parameters to be measured. Firouz and Alimardani (2016) developed and calibrated a portable capacitive moisture meter to predict the moisture content of grains and seeds by measuring the dielectric constant of the sample. Dielectric measurement of seeds was carried out at 5 levels of moisture content and then the moisture content of each sample was measured using oven method. The experimental data were fitted to a quadratic model and the results were in agreement with the similar reported papers for corn. Sacilik and Colak (2010) proposed the second and third-order polynomial equations to describe the existing relationship between dielectric properties and moisture content of corn seed. The study obtained the best results at $1 \mathrm{MHz}$ with $\mathrm{R} 2$ of 0.998 . They extracted the linear calibration equations over a temperature range of $10^{\circ} \mathrm{C}$ to $30^{\circ} \mathrm{C}$ to predict moisture content of grains and seeds and the system was calibrated for wheat, corn, millet, lintel, pea and black-eyed pea. Akesson and Slatteke (2006) modelled and calibrated a paper machine dryer section where they demonstrated an approach towards machine calibration that employs models for multi variable parameters in operation. From this literature of similar machines, a simpler calibration model equation can be employed that predicts and sets the RWD drying temperature within a desired range. The refractance window drying system is a novel drying method which utilizes circulating water at $95^{\circ} \mathrm{C}$ to $97^{\circ} \mathrm{C}$ as a means of carrying thermal energy to products to be dried (Abonyi et al., 2002). The refractance window dryer (RWD) comprises of a moving conveyor belt onto which products are placed to be dried and a water pump that circulates hot water beneath and in contact with the transparent plastic conveyor belt (Nindo et al., 2003). Several conventional dryers are either designed for specific food products or would require a technical operator with the knowledge of food drying temperatures to dry multiple products. This is costly since it requires several dryers and high-level training of operators. The objective of the RWD calibration therefore was to ensure that the dryer is able to dry different products placed onto the conveyor belt with ease by selecting the product using a knob. 


\section{MATERIALS AND METHODS}

\section{Design of dryer calibration circuit}

The calibration system comprises of a potentiometer knob that sends signals to a controller board which processes them and sets the drying temperature within a desirable range. This system was intended to adjust the optimum drying temperature of the dryer for a specific food product as the performance parameter. A potentiometer knob was employed to select for a specific product which would send a specific voltage to the Arduino board that was read.
The three potentiometer wires were connected to the controller board (Arduino) as follows; the first wire went to ground (GND) from one of the outer pins of the potentiometer. The second wire went from $5 \mathrm{~V}$ pin on the board to the other outer pin of the potentiometer and the third went from Analogue input (A0) pin to the middle pin of the potential meter as illustrated in FIGURE 1 . The analog Read () command in the computer code converts the input voltage range, to a digital value between 0 and 1023. This was achieved by the analog-to-digital converter inside the microcontroller.

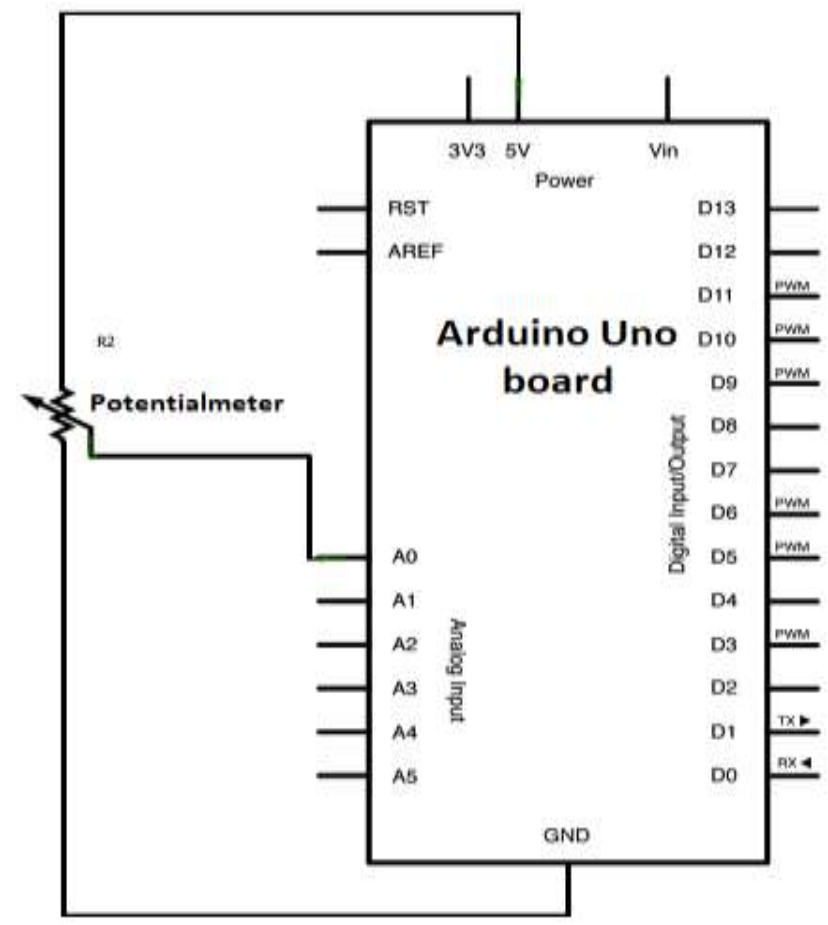

FIGURE 1 : Potentiometer connection circuit design

\section{Calibration of the system}

During calibration, a temperature range with minimum (MIN) and maximum (MAX) values of boiler temperature were set beyond which commands would be executed. This was the range within which all food products are expected to dry using the refractance window dryer. By turning the knob of the potentiometer and reading from the Arduino serial monitor, markings were made on the label that match the optimal drying temperature of the different products from literature.
Hence turning the knob set the desired temperature range on the label within which the product was dried such that, below this temperature the heater would go on and above this temperature the heater would go off. An accurate scaled trace of the potentiometer was drawn on a plain piece of paper as illustrated in FIGURE 2. to mark out the angular sweeps.

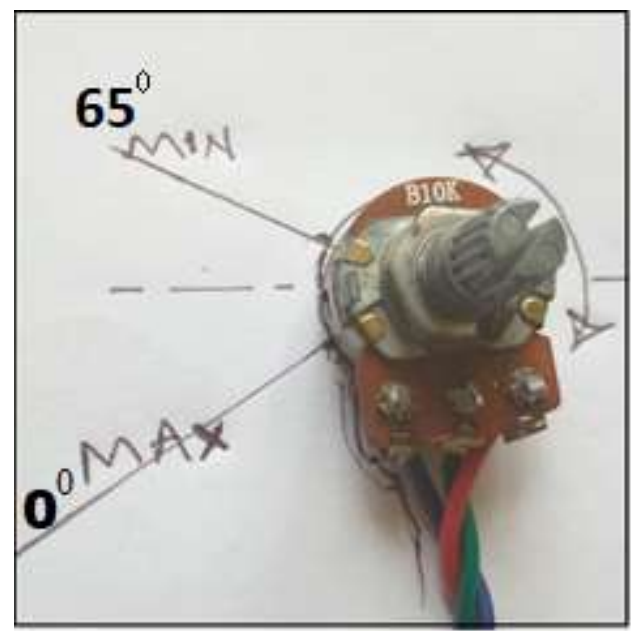

FIGURE 2 : Potentiometer calibration to scale 
According to optimization studies done on the RWD on different food products and studies done by Feng et al (1999), the optimum drying temperature for the three selected products is $95^{\circ} \mathrm{C}$ hence calibration for optimum drying was done at $95^{\circ} \mathrm{C}$. The potentiometer knob was turned to minimum (MIN) and then maximum (MAX) and markings were made on the paper. The angle through which the potentiometer was swept was recorded in degrees and the corresponding temperatures read on the serial monitor were recorded. By observing the set temperature on the serial monitor and comparing it with the swept angle of the potentiometer, a linear relationship was derived which described the best calibration equation of the system shown in Equation 1.

From $y=m x+c$

Equation 1

Where $\mathrm{X}$ is the potential meter setting, $\mathrm{Y}$ is the desired temperature (serial monitor reading) and the gradient $\mathrm{m}$ is calculated as shown in the Equation 2.

Gradient $\mathrm{m}=\frac{\mathrm{Y} 2-\mathrm{Y} 1}{\mathrm{X} 2-\mathrm{X} 1}$

Equation 2

\section{Performance testing of the dryer calibration system}

The calibration system was tested to ensure that the dryer is able to dry the selected products and other products. The set-up involved assembling the entire automation system. Since the all the selected products dried at $95^{\circ} \mathrm{C}$, the desired temperature was set to $95^{\circ} \mathrm{C}$ using the knob and the actual boiler temperature monitored from the serial monitor. The system results were read by PLX-DAQ software and tabulated in Excel. The mean velocity of the water pump was calculated from the continuity equation of fluid flow in Equation 3:

Velocity $\quad \mathrm{V}=\frac{\text { Discharge }}{\text { Crossectional area of flow }}$

Equation 3

The calibration system was further tested for accuracy by comparing the desired knob temperature and the actual boiler temperature. Seven test runs were conducted to test the accuracy of the system at 7 calibration temperatures. At every temperature, the knob was moved to set the desired temperature, the system switched on and results recorded using PLX-DAQ software that tabulated into excel.
The average boiler temperature at every calibration temperature was calculated from Equation 4.

Average Temperature $=$

Sumation of Boiler temperatures above the desired temperature Total number of temperatures readings

Equation 4

The temperatures considered in calculation of the average water temperature were those recorded 2 minutes after the desired temperature was attained because a stable temperature was expected be have been achieved within that time. Results for the actual boiler temperature at every desired temperature were tabulated and a comparison bar graph generated of desired temperature and actual boiler temperature. For calculation of percentage error and accuracy percentage, Equation 5 and Equation 6 were used. Where Parameter $e_{\text {n }}$ stated the error percentage, parameter $A_{\mathrm{n}}$ stated the accuracy percentage, and parameter $Y_{\mathrm{n}}$ stated the results of desired temperature set by the knob and parameter $X_{\mathrm{n}}$ stated the result of the actual water temperature attained by the system.

\section{Error percentage}

$\boldsymbol{e}_{\mathbf{n}}=\left[\frac{Y n-X n}{Y n}\right] X 100$

Equation 5

Accuracy percentage

$\mathbf{A}_{\mathbf{n}=100}-100-\left[\left[\frac{Y n-X n}{Y n}\right] X 100 \%\right]$

Equation 6

The error percentage and accuracy percentage were tabulated for each temperature and the average percentage accuracy of the system calculated.

\section{Computer program design for the calibration of the dryer}

A computer program code for programming the potentiometer system was written using Arduino software and uploaded on to the Arduino board via a USB drive. A program was written to receive the analog signals from the potentiometer (analogRead [POT]) and convert it into digital signal to be read by the microcontroller. FIGURE 3 illustrates the logical flow of information through the calibration system to match the desired potentiometer setting with the boiler water temperature.

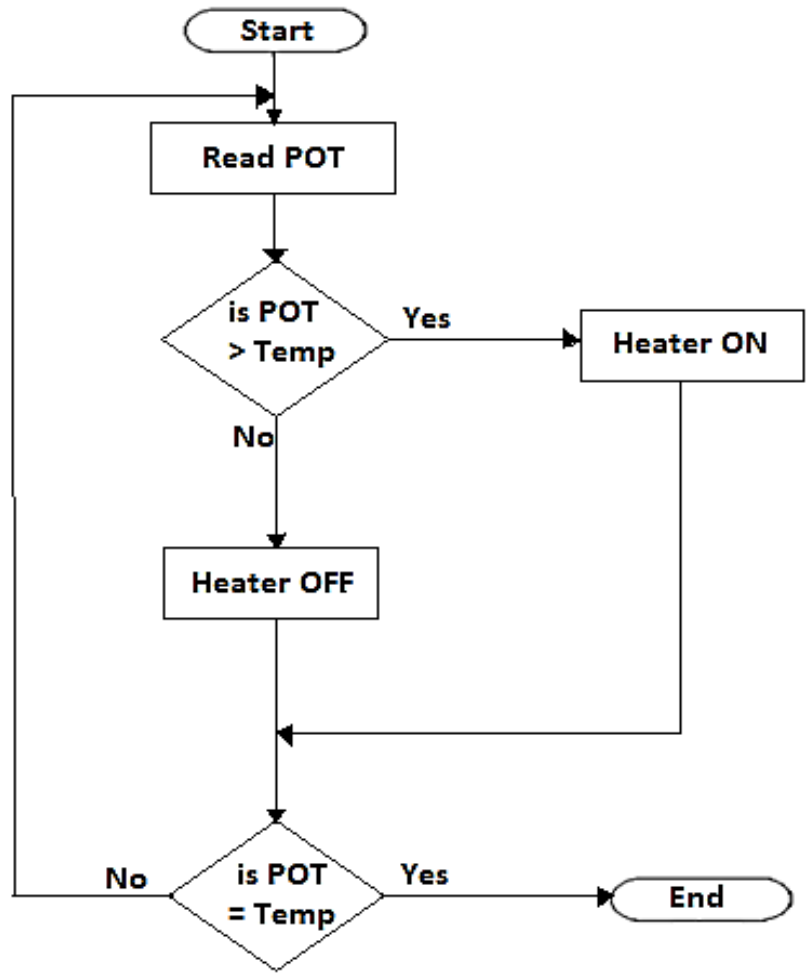

FIGURE 3: A data flow diagram for the calibration system of the dryer 


\section{RESULTS AND DISCUSSIONS}

Calibration of the system for different food products

Calibration was done at $95^{\circ} \mathrm{C}$ and the minimum and maximum values for both potentiometer setting and serial monitor reading were recorded as shown in TABLE 1.

TABLE 1: Actual potentiometer setting and serial monitor reading $\left({ }^{\circ} \mathrm{C}\right)$

\begin{tabular}{lcc}
\hline Level & $\begin{array}{c}\text { Potentiometer setting } \\
\text { (deg) X }\end{array}$ & $\begin{array}{c}\text { Serial monitor reading } \\
\left({ }^{\circ} \mathbf{C}\right) \mathbf{~ Y}\end{array}$ \\
\hline MIN & 0 & 65 \\
MAX & 295 & 95 \\
\hline
\end{tabular}

Gradient $\mathrm{m}$ was calculated from Equation 2 as 0.10169 $(10.27 \%)$ and using Y1 and X1 intercept $\mathrm{c}$ was found to be 65. Knowing the gradient and intercept, a calibration equation for the desired temperature was developed as Equation 7

Calibration equation; $\mathrm{Y}=0.10169 \mathrm{X}+65$

Equation 7

Substituting " $\mathrm{X}$ " in Equation 7 gives a desired temperature $\mathrm{Y}$ as $94.9996{ }^{\circ} \mathrm{C}$ hence the temperature selected is $95^{\circ} \mathrm{C}$. After calibration at $95^{\circ} \mathrm{C}$, the system was switched on and the graph in Figure 4 was extracted after Excel tabulation. From the calibration Equation 7, the intercept $\mathrm{c}$ of $65^{\circ} \mathrm{C}$ indicated that the conveyor belt and water pump both start at $65^{\circ} \mathrm{C}$ which is the minimum set value for the range of the potentiometer (MIN) above which most food products are optimally dried which agrees with Feng et al. (1999). The positive gradient of $10.12 \%$ indicates that the desired temperature scale increases as the angel of the potentiometer knob is turned further in the clockwise direction. Calibration results show that the desired temperature remains constant throughout the entire experiment at $95^{\circ} \mathrm{C}$. This is because it is the set temperature by the potentiometer upon which the boiler temperature is regulated and it does not change for a specific operation. When the water temperature rose from point $\mathrm{A}$ on the graph at $31.19^{\circ} \mathrm{C}$ to $\mathrm{B}$ at $92.12^{\circ} \mathrm{C}$, the water pump was switched on by the system and 3 seconds later, the conveyor belt was also turned on. This is because the water conveyance system was programmed to give the water pump a 3 second head start ahead of the conveyor belts to ensure that the cool water in the tray can be replaced with the hot water at the desired temperature.
With the heater on, the water temperature kept rising to a temperature D of $98.06^{\circ} \mathrm{C}$ as shown in Figure 4 . With the conveyor belt and water pump still in operation, this temperature was maintained for the remaining testing period with a difference of $\pm 1^{\circ} \mathrm{C}$. This is because at this point even when the heater was switched off, the water volume in the boiler had gained enough heat energy to maintain this high temperature range without rapidly falling below the desired. The heater was switched off when the temperature curve reached point $\mathrm{D} 98.06^{\circ} \mathrm{C}$. This is because this temperature is above the calibrated acceptable temperature range of $95 \pm 3^{\circ} \mathrm{C}$ that the system is programmed to maintain. Results displayed in Figure 4 reveal that the highest water temperature recorded in the system was $98.06^{\circ} \mathrm{C}$ and this can be attributed to the fact that after the desired temperature was reached, the system turned off the heater hence limiting the water temperature from significantly exceeding this range. At point $C$ on the graph, an anomaly is seen where the water temperature appears to suddenly drop from $95.75^{\circ} \mathrm{C}$ to $63.81^{\circ} \mathrm{C}$ as shown by the sudden dip in the temperature graph. This can be attributed to a malfunction in the DS18B20 temperature sensor communication with the controller board. However, it is seen that the conveyor belt movement, water pump state and heater all remained functioning undisturbed hence, the system proved robust to external interference to the dryer environment. From the calibration equation, the calibrated label in Figure 5 was developed which indicates the potentiometer angular settings on the inside and the set temperature degrees on the outside.

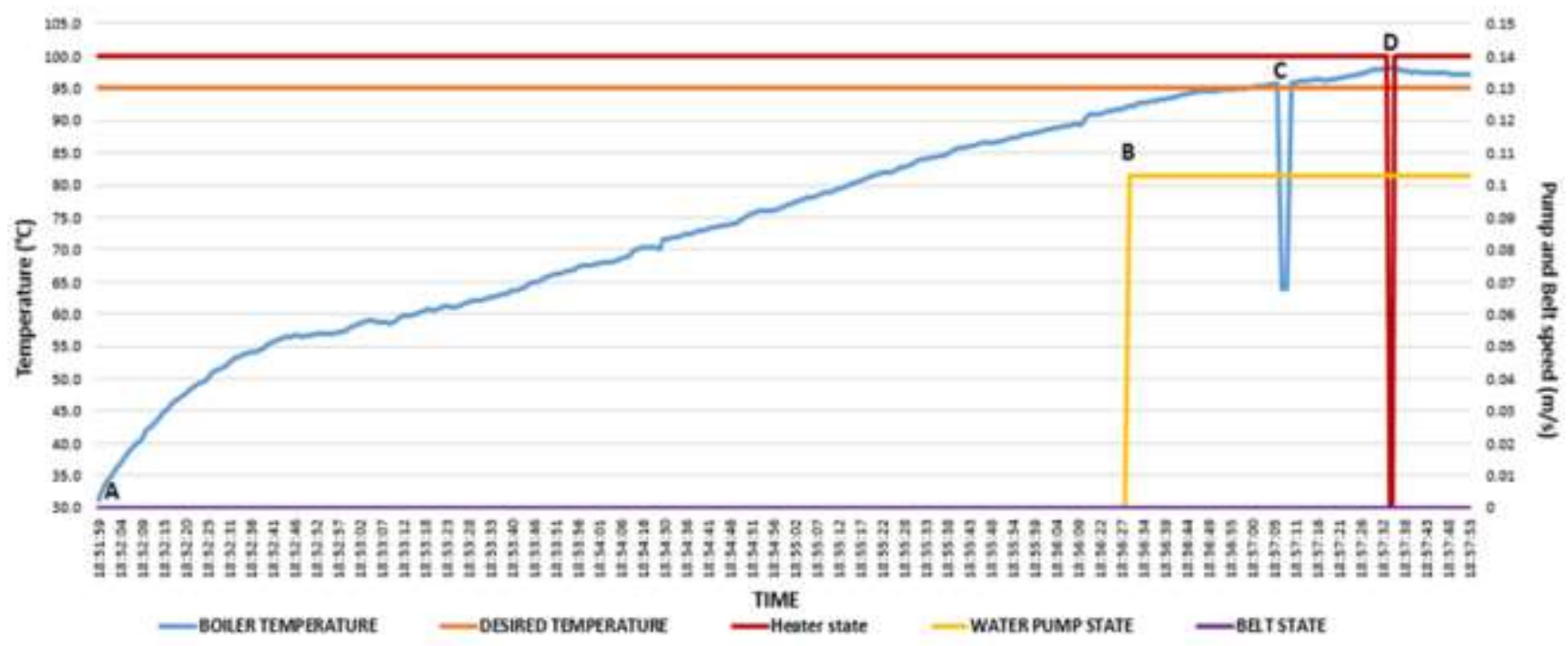

FIGURE 4: Variation of desired actual boiler temperature with belt state and water pump state 


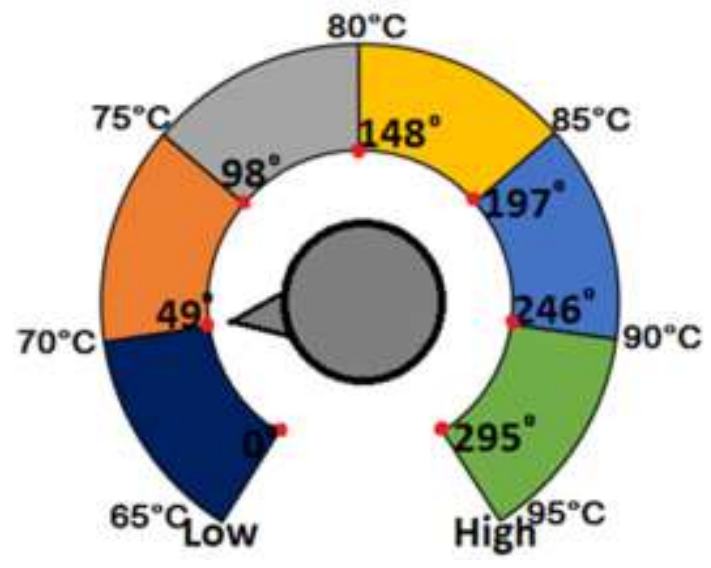

FIGURE 4: The RWD calibrated label

\section{- Results for performance testing of the calibration} system for accuracy

Upon computation, results for dryer calibration at $65^{\circ} \mathrm{C}$ $70^{\circ} \mathrm{C}, 75^{\circ} \mathrm{C}, 80^{\circ} \mathrm{C}, 85^{\circ} \mathrm{C}, 90^{\circ} \mathrm{C}$ and $95^{\circ} \mathrm{C}$ were recorded in TABLE 2. FIGURE 5. shows that the percentage temperature error between the desired water temperature and actual boiler temperature kept increasing from $-5.7 \%$ at $65^{\circ} \mathrm{C}$ to $1.3 \%$ at $95^{\circ} \mathrm{C}$. There was a minus error percentage as the actual temperatures in the boiler were larger compared to the desired water temperature set by the knob. The system had an accuracy of $97.6 \%$ at maintaining the boiler temperatures to the desired temperature and a magnitude of error of $2.4 \%$. This error can be attributed to the changes in the temperature gradient between the locations of the heating element to the point where the sensor picks the heat inside the water. These results were in agreement with findings of Martono et al. (2019) who observed a negative average percentage error and an average accuracy of more than $100 \%$. It was observed that the calibration error generally reduced as the desired temperatures approached the maximum value of $95^{\circ} \mathrm{C}$
This can be attributed to the higher rate of heat losses in the water body which increased with increasing water temperatures. FIGURE 6 is presented as an example of calibration temperature at $65^{\circ} \mathrm{C}$ and results reveal that the temperature rose steadily from $25.13^{\circ} \mathrm{C}$ until a point marked X was reached when the water temperature in the boiler matched the desired temperature set by the knob. At this point, the rate of temperature increase with time reduces and the temperature remained within an acceptable range of $65 \pm 3^{\circ} \mathrm{C}$. The reduction in the rate of increase of temperature can be attributed to the fact that at this point, the heater was switched off by the system as programmed by the code hence the temperature stopped rising rapidly. All the graphs generated at the different temperatures had a point marked X where the actual boiler temperature matched the desired temperature beyond which temperatures stopped rising rapidly. The percentage error and percentage accuracy of the calibration system were computed and tabulated from Equations 5 and 6.

TABLE 2: Variation of desired water temperature with actual water boiler temperature

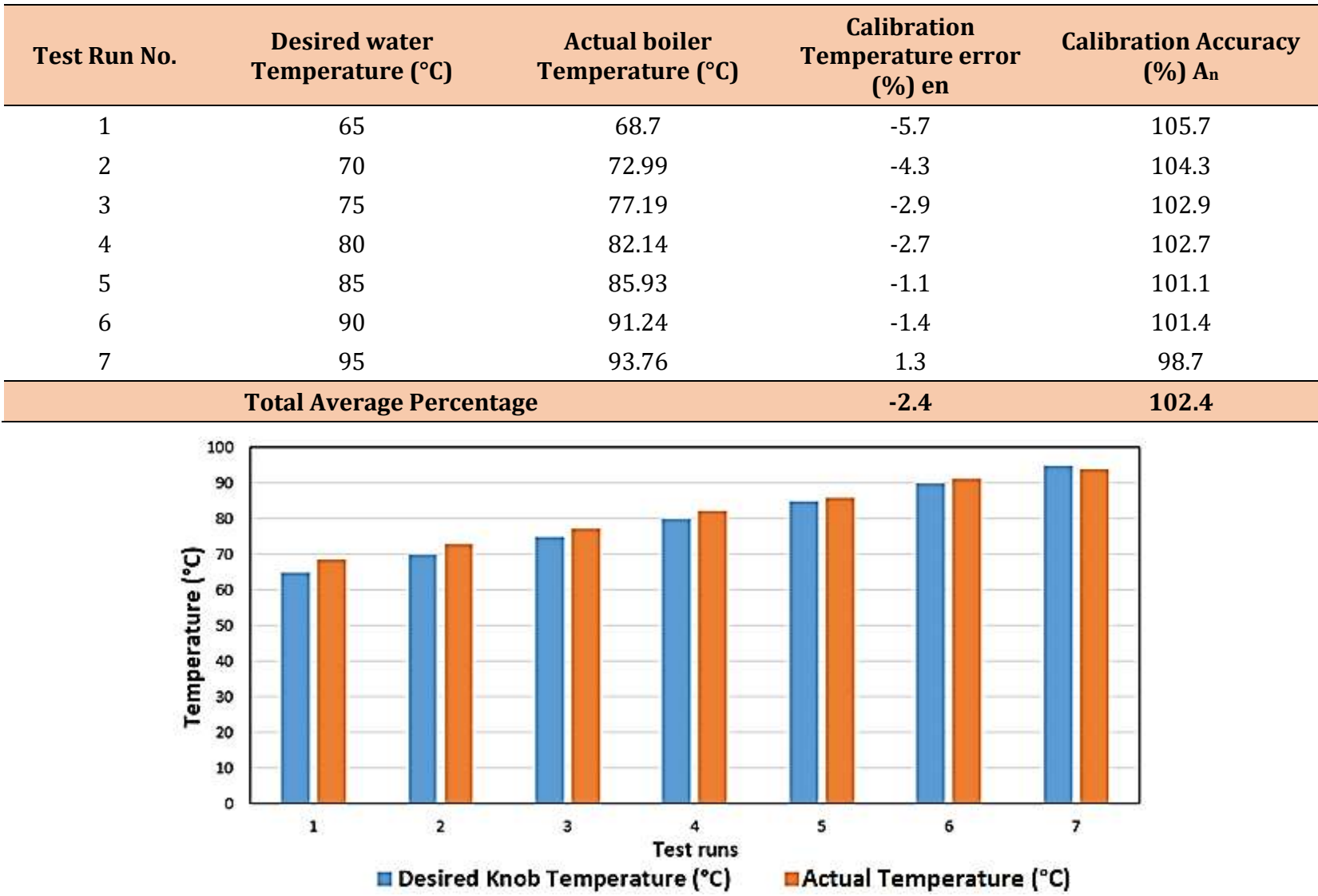

FIGURE 5: Comparison results between desired water temperature and actual boiler temperature 


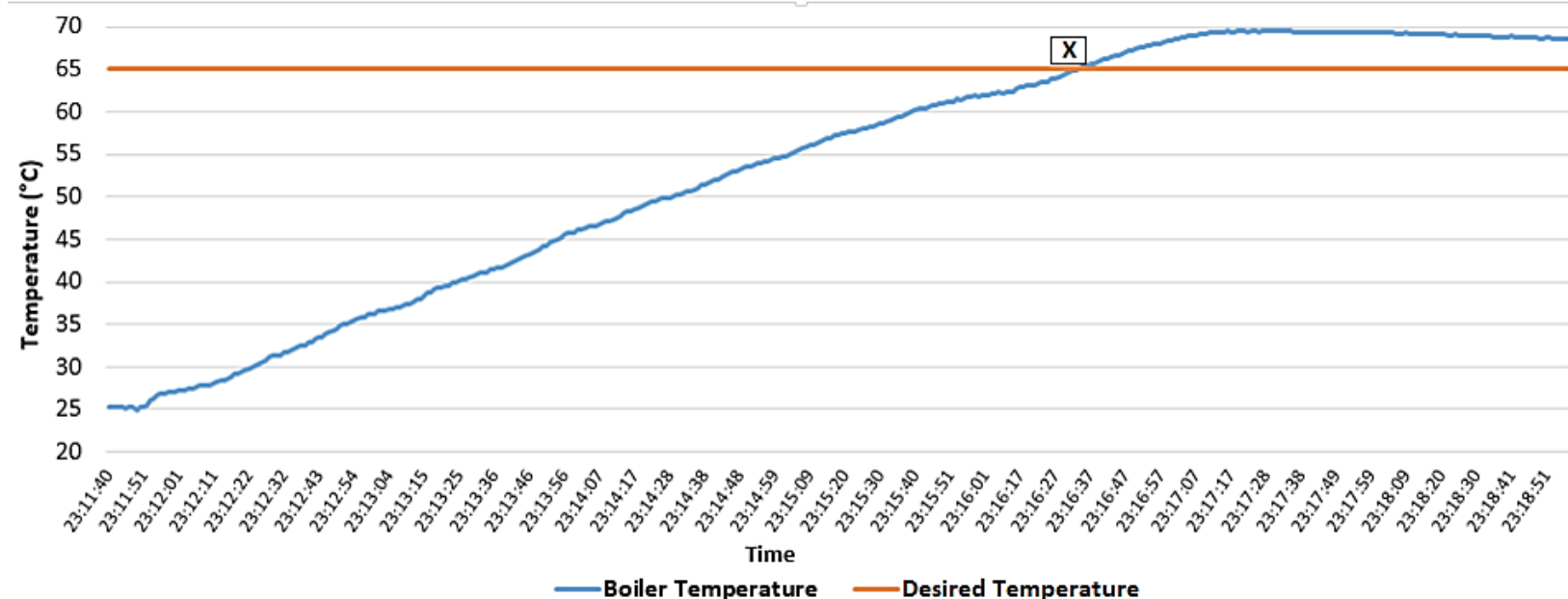

FIGURE 6: Calibration of the system at $65^{\circ} \mathrm{C}$

\section{Computer program code for the calibration system}

The computer system was written in Arduino environment to control the calibration system. To make the program runnable, 2 functions were used; the set-up () - called once the start of the program and loop () - called repeatedly as long as system is on and powered. Following are some of the codes that were developed to run the automation system of the dryer and their implication in the script explained.

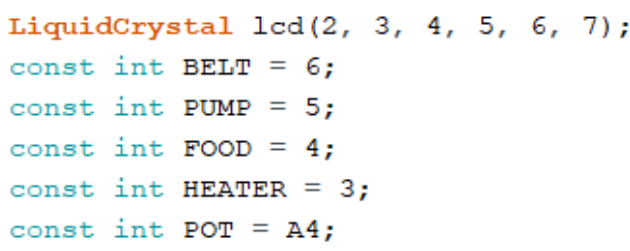

The above code section was used to declare variables that represented the different components when programming and the different board pins onto which each component was connected.

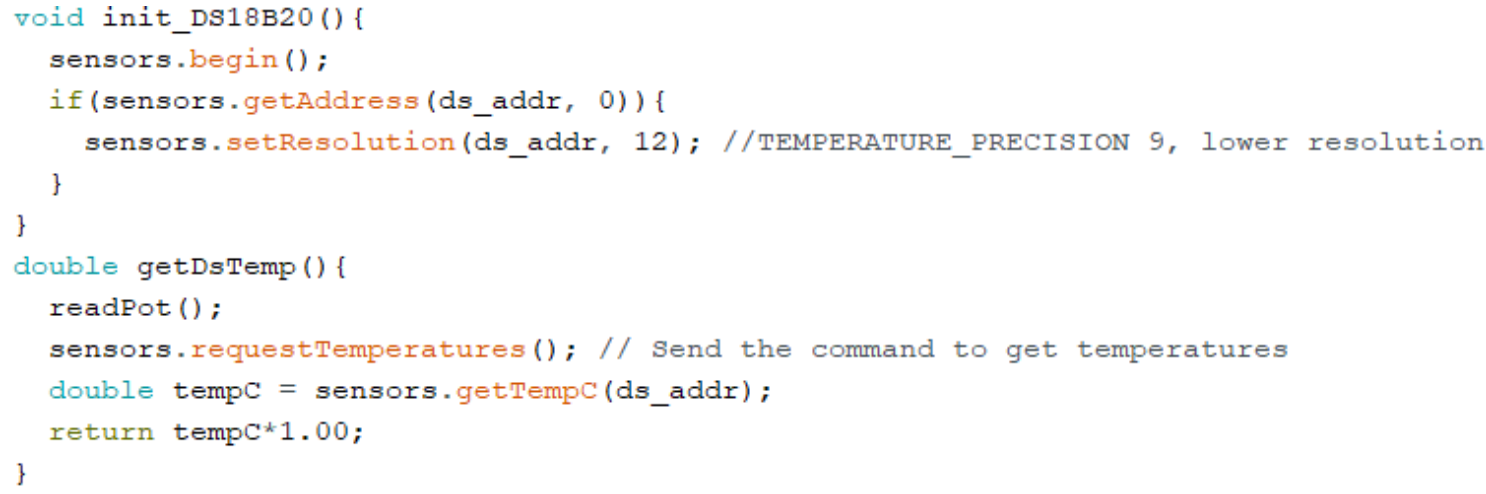

The code was used to command the DS18B20 temperature sensor to read the boiler temperature (getDsTemp) in degrees, read the potentiometer set value (readPot) and also to set the temperature precision and adjust initial temperature resolution to be displayed on the LCD.

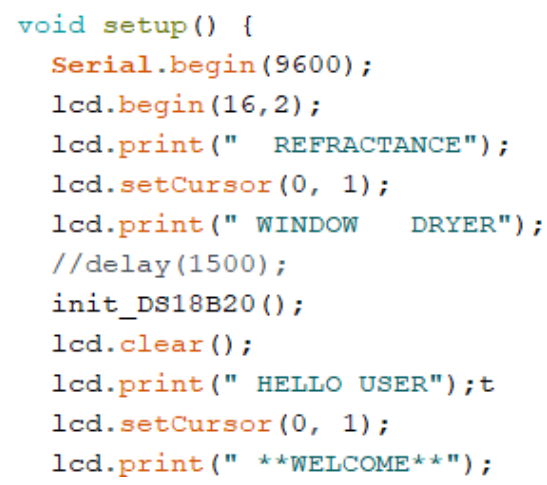

In the void setup section code above, the LCD is commanded to begin displaying and the initial welcome texts on the display were declared. The text dislayed was "REFRACTANCE WINDOW DRYER -HELLO USER-WELCOME." The screen was commanded to clear after a specific statement and reprint the next word on the next line. In the void setup section, the output and input devise were declared as follows: (BELT, OUTPUT), (PUMP, OUTPUT), (HEATER, OUTPUT), (FOOD, INPUT_PULLUP) and (POT, INPUT). 
\}

void loop () i

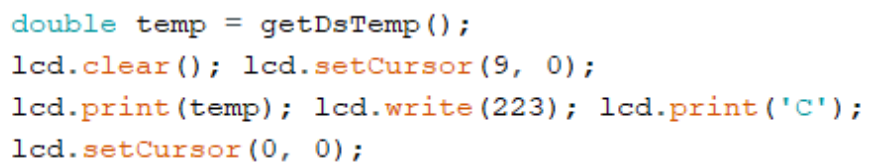

In the void loop section of the code below, commands that needed to be repeated throughout the system in a loop were developed. The temperature sensor was commanded to continuously read the temperature and display it on the screen in ${ }^{\circ} \mathrm{C}$, and then set the cursor back to the first line first space on the screen.

\}

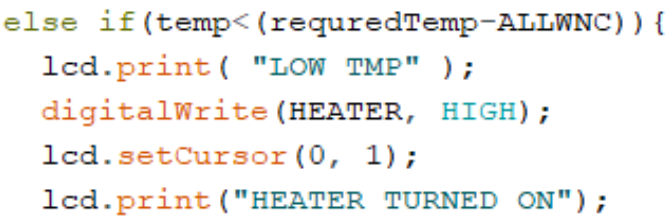

If the water temperature was less than the required temperature, the first line in the code above checked this condition and the system commanded the LCD to display "LOW TMP", immediately switch on the water heater and the LCD displayed "HEATER TURNED ON". The computer coding was successful and the program proved effective to operate all the systems and commands involved.

\section{CONCLUSIONS}

From the results, it can be seen that only one set of calibration was successfully done at $95^{\circ} \mathrm{C}$ since all the selected food products are optimally dried at this temperature. The computer program written in Arduino was run successfully hence the design and calibration displayed a high sense of reliability on the computer program. The design displayed a high level of robustness since the system was able to maintain the desired temperature throughout the entire testing. The Arduino Uno calibration system was able to attain a maximum temperature of $98.06^{\circ} \mathrm{C}$, which is laudable since most food products are dried below this temperature. In the overall system testing, the system had a calibration accuracy of $97.6 \%$ and an error value of $2.4 \%$. From the calibration equation, a calibrated label was developed which made it possible for the dryer to dry products between $65^{\circ} \mathrm{C}$ and $95^{\circ} \mathrm{C}$.

\section{ACKNOWLEDGEMENT}

This research was funded by the Bioresources Innovations Network for Eastern Africa Development Programme (BioInnovate Africa) - Grant\#: BA/C1/2017-01_MAK

\section{REFERENCES}

[1] Abonyi, B. I., Feng, H., Tang, J., Edwards, C. G., Chew, B. P., Mattinson, D. S., \& Fellman, J. K. (2002). QualityRetention in Strawberry and Carrot Purees Dried with RW System.pdf. JOURNAL OF FOOD SCIENCE 1051, 67(2).

[2] Akesson, J., \& Slatteke, O. (2006). Modeling , Calibration and Control of a Paper Machine Dryer Section. The Modelica Association.

[3] Carmignato, S. (2019). Calibration. CIRP Encyclopedia of Production Engineering, (January). https://doi.org/10.1007/978-3-662-53120-4
[4] Feng, H., Tang, J., \& Cavalieri, R. P. (1999). Combined Microwave And Spouted Bed Drying of Diced Apples: Effect Of Drying Conditions On Drying Kinetics And Product Temperature. Drying Technology: An International Journal, (October 2014), 37-41. https://doi.org/10.1080/07373939908917668

[5] Firouz, M. S., \& Alimardani, R. (2016). Design , Development and Calibration of a Portable Capacitive. Sensors and Transducers Journal, 126(June), 24-32.

[6] JCGM. (2008). International vocabulary of metrology - Basic and general concepts and associated terms (VIM). International Organization for Standardization Geneva ISBN, 3(Vim), 104. https://doi.org/10.1016/0263-2241(85)90006-5

[7] Martono K.Y, Eko D.W, \& B, Y. (2019). Performance Analysis On The Arduino Uno Microcontroller-Based Weight Measurement. Journal of Theoretical and Applied Information Technology, 97(7).

[8] Michell Instruments. (2015). The fundamentals of moisture calibration, (June), 1-12.

[9] Nindo, C. I., Feng, H., Shen, G. Q., Tang, J., \& Kang, D. H. (2003). Energy utilization and microbial reduction in a new film drying system. Journal of Food Processing and Preservation, 27(2), 117-136. https://doi.org/10.1111/j.17454549.2003.tb00506.x

[10] Sacilik, K., \& Colak, A. (2010). Determination of dielectric properties of corn seeds from 1 to 100 MHz. Powder Technology, 203(2), 365-370. https://doi.org/10.1016/j.powtec.2010.05.031 